\title{
Can Oxytocin influence Placebo and Nocebo effects in Pain?
}

\section{A.Skvortsova ${ }^{1,2}$, D.S.Veldhuijzen ${ }^{1,2}$, H. van Middendorp1,2, O.van den Bergh ${ }^{3}$,}

L.Colloca ${ }^{4}$, A.M.W.Evers ${ }^{1,2,5}$

1Department of Health, Medical and Neuropsychology, Leiden University, the Netherlands, ${ }^{2}$ Leiden Institute for Brain and Cognition, the Netherlands, ${ }^{3}$ KU Leuven - University of Leuven, Belgium, ${ }^{4}$ University of Maryland Leiden, School of

Nursing, ${ }^{5}$ Psychiatry Department, Leiden University Medical Center, the Netherlands

\section{Background}

Placebo effects are favorable treatment outcomes not due to the treatment mechanism itself while nocebo effects are unfavorable treatment outcomes, e.g., side effects of medicines.

Two mechanisms can induce placebo/nocebo effects:

- Expectations (e.g., of improvement)

- Classical conditioning ${ }^{1}$

Placebo effects were found for pain $^{2}$, itch $^{3}$,

but size of the effects varies across the studies

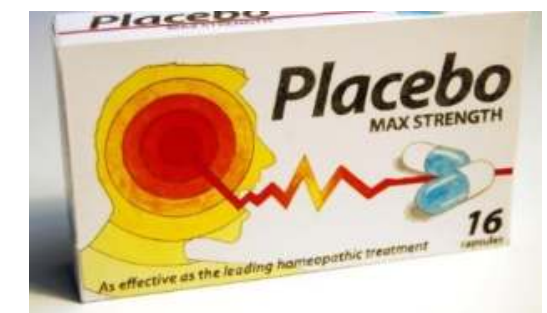

\section{Study 1:}

Research question: Does oxytocin enhance placebo effects for pain and itch in healthy females?

RCT double blind, 4 groups:

- Oxytocin (24IU) with suggestions

- Oxytocin without suggestions

- Control with suggestions

- Control without suggestions

108 healthy females, $18-35$ y.o.

Outcomes:

Subjective pain ratings $(0-10$

VAS)

Subjective itch ratings (0-10 VAS)

\begin{tabular}{|cccc|}
$\begin{array}{c}\text { Baseline Cold } \\
\text { Pressor Test }\end{array}$ & $\begin{array}{c}\text { Verbal suggestions } \\
\text { Spray }\end{array}$ & $\begin{array}{c}\text { Cold } \\
\text { Pressor Test }\end{array}$ \\
\hline & 0 & 0 & 0 \\
& 0 & & $\begin{array}{c}\text { Histamine } \\
\text { test }\end{array}$ \\
\hline
\end{tabular}

Cold water $+4{ }^{\circ} \mathrm{C}$

1 minute

Outcome: pain

ratings every 15

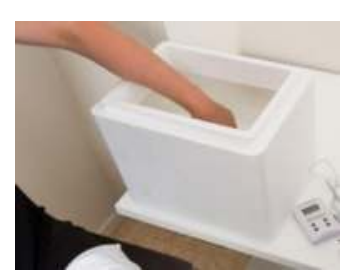

2,5 minutes itch stimulation

Outcome: itch rating

every 30 seconds

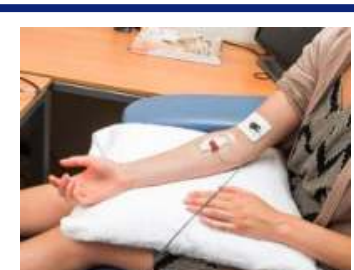

Positive suggestions: "This spray contains oxytocin. It has been

demonstrated in previous studies that oxytocin decreases pain and itch

sensitivity. We expect that after receiving oxytocin, you will also experience

less pain during the CPT and less itch during the histamine test".

Study aim: Investigate weather oxytocin enhances placebo effects and decreases nocebo effects for pain and itch. Oxytocin is a hypothalamic hormone that might influence placebo effect through its positive effects ${ }^{4}$

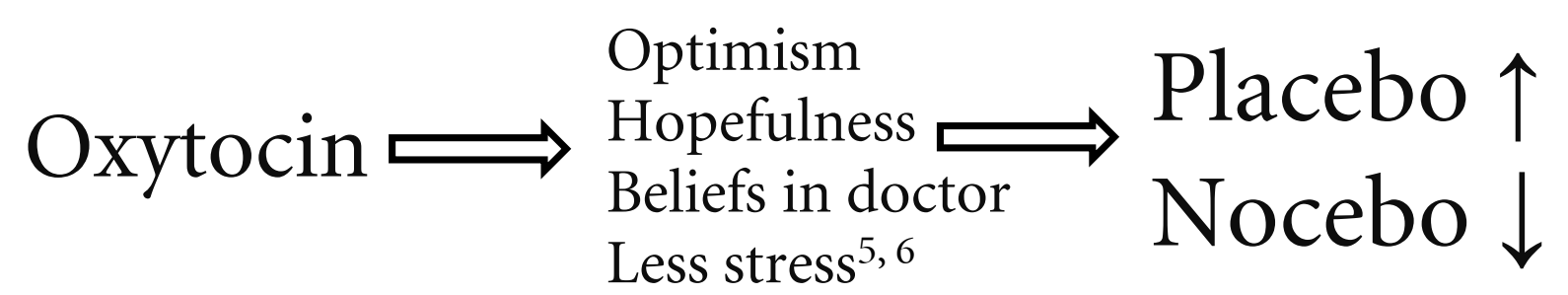

\section{Study 2:}

Research question: Does oxytocin enhance placebo effect and decrease nocebo effect for pain in healthy males?

RCT double blind, 2 groups:

- Oxytocin (40 IU)

- Control

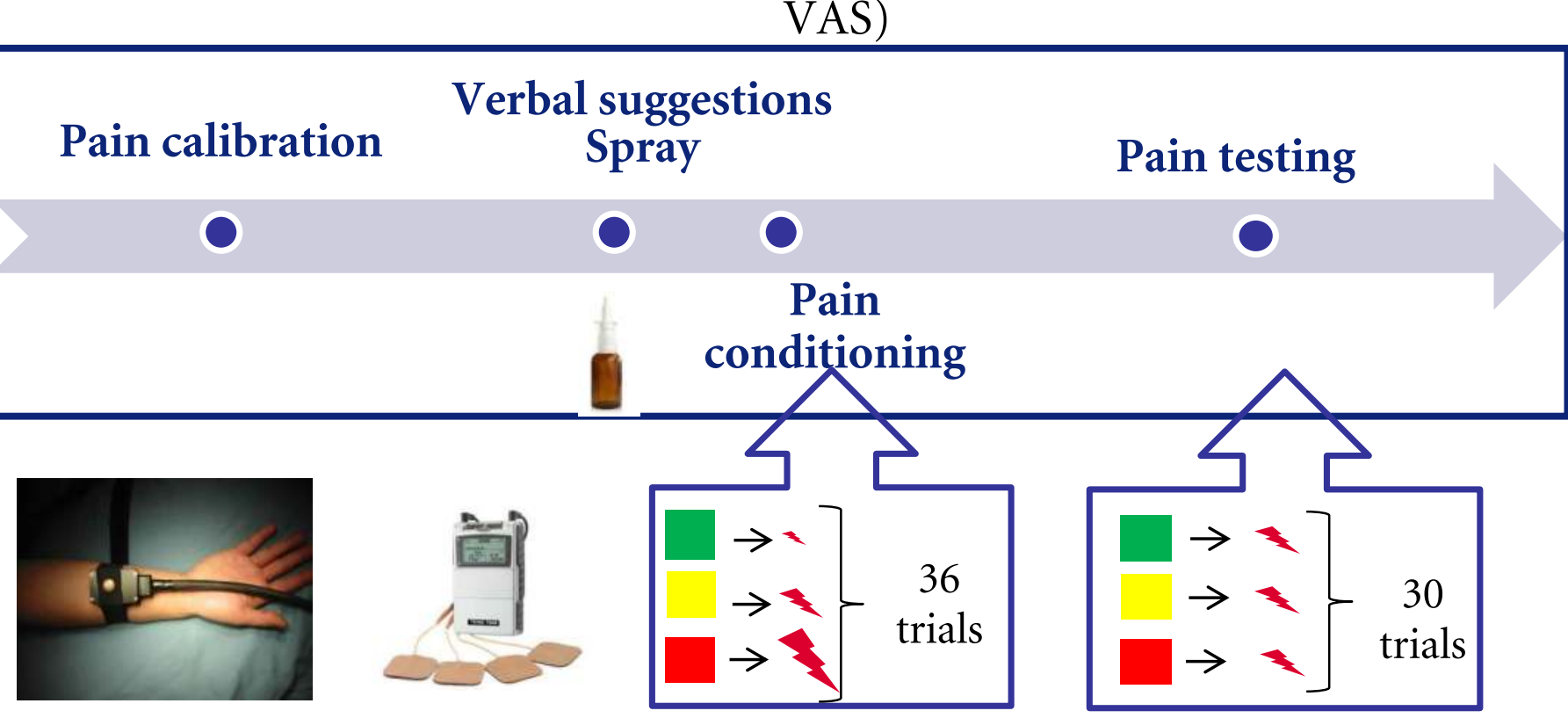

Suggestions: "Before each stimulus you will see a color on the screen. Green color will indicate that the TENS is in the pain-relieving mode and will decrease your pain levels. Yellow color will indicate that the TENS is off and will not modify your pain levels. Red color will indicate that the TENS is in the pain enhancing mode and will enhance your pain sensitivity".

\section{Results}

No suggestions

Oxytocin
Study ${ }^{1} 7$ Itch

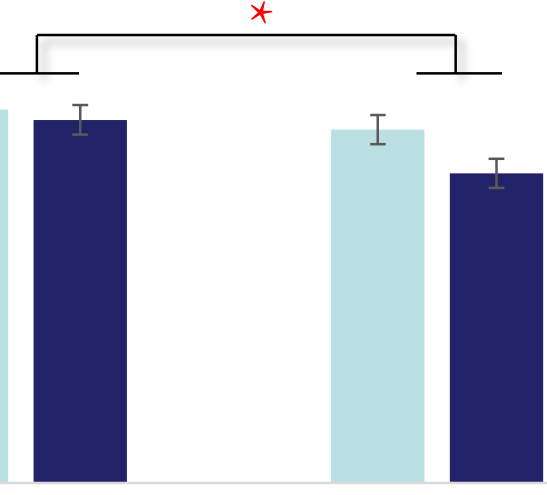

Positive suggestions - Control

6
5
4
3
2
1
0

No suggestions Oxytocin - Control

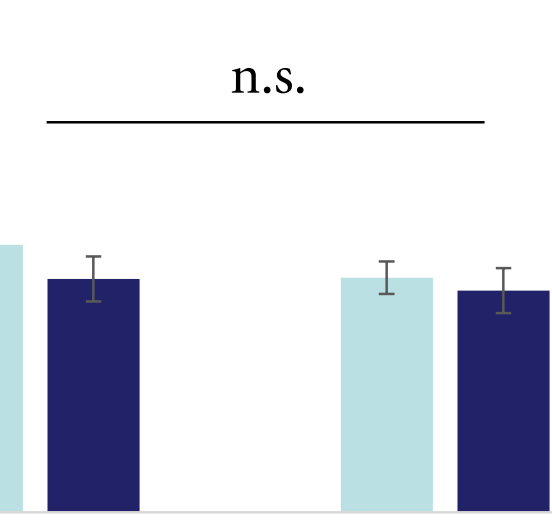

Positive suggestions

\section{Conclusions}

- Oxytocin does not influence placebo and nocebo effects neither in females nor in males and with various dosages;

- Positive verbal suggestions induce placebo effect for pain and decrease pain sensitivity;

- Positive verbal suggestion with conditioning induce placebo and nocebo effect and decrease and increase pain sensitivity.
Study 2

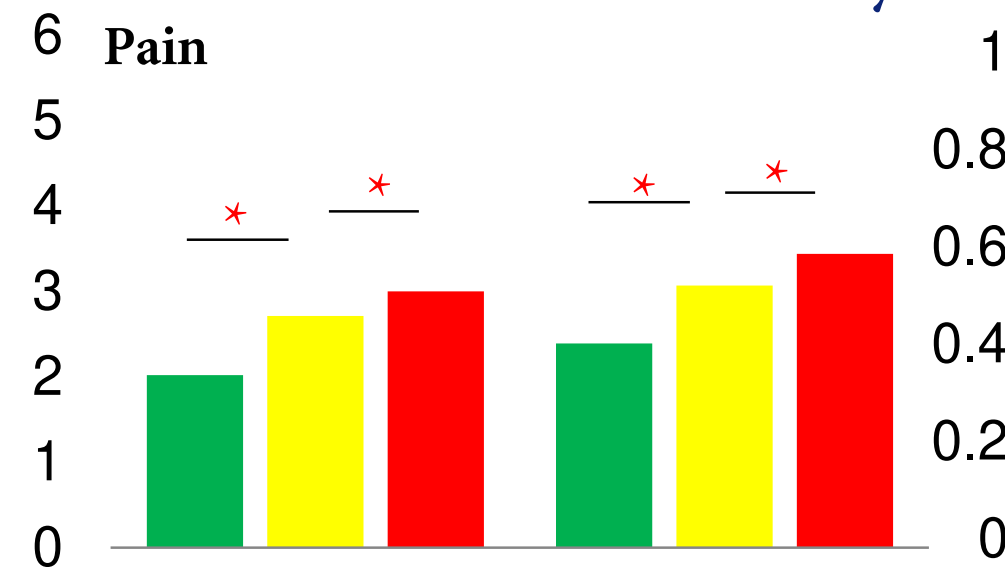

Oxytocin

Control

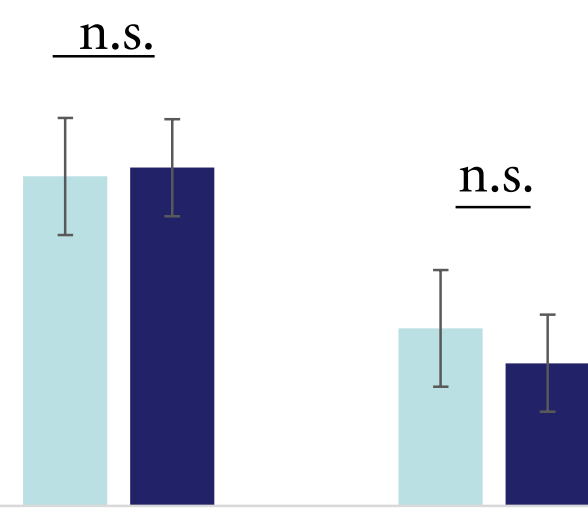

Placebo Effect Nocebo Effect Oxytocin $\square$ Control
80 healthy males, $18-35$ y.o.

Outcomes:

Subjective pain ratings (0-10 Nocebo $\downarrow$ 